\title{
MITO, DIVERSIDADE CULTURAL E EDUCACÃ̃: NOTAS SOBRE A INVISIBILIDADE GUARANI NO RIO GRANDE DO SUL E ALGUMAS ESTRAIÉGIAS NATIVAS DE SUPERACÃOA
}

\author{
Ceres Karam Brum* \\ Universidade Federal de Santa Maria - Brasil \\ Suzana Cavalheiro de Jesus ${ }^{* *}$ \\ Universidade Federal do Pampa - Brasil
}

Resumo: A questão da invisibilidade guarani no Rio Grande do Sul se assenta em um conjunto de elementos que perpassam a história dessas populações de diferentes formas. Dentre eles se destacam narrativas produzidas por não indios e que apresentam visões recorrentes e idealizadas que têm como referentes expressões do folclore gaúcho. Nos últimos anos, porém, perspectivas indigenas passam a integrar as significações acerca desse passado e questionar a invisibilidade guarani no Rio Grande do Sul. Trata-se dos filmes produzidos pelo Coletivo Mbya-Guarani de Cinema/Vídeo nas Aldeias. Ao longo deste texto desejamos analisar algumas relações entre mito, diversidade cultural e educação, tomando como base essas representações acerca do passado missioneiro, acionadas a partir do Sítio Arqueológico de São Miguel Arcanjo e da figura de Sepé Tiaraju.

Palavras-chave: educação, invisibilidade, Mbya-Guarani, mito.

Abstract: The issue of invisibility Guarani in Rio Grande do Sul is based on a set of elements that permeate the history of these people in different ways. Among these stand out narratives produced by non-Indians and with recurring visions and idealized whose expressions regarding the gaucho folklore. In recent years, however, indigenous perspectives become part of the meanings about this past and question the Guarani invisibility in Rio Grande do Sul. These are the films produced by the

* Contato: cereskb@terra.com.br.

** Contato: suzanacavalheiro@yahoo.com.br.

Horizontes Antropológicos, Porto Alegre, ano 21, n. 44, p. 201-227, jul./dez. 2015 http://dx.doi.org/10.1590/S0104-71832015000200009 
Collective Mbya-Guarani Film / Video in the Villages. Throughout this text we want to propose an analysis between myth, cultural diversity and education, based on these representations about the missionary past, driven from the Archaeological Site of St. Michael the Archangel and Sepé Tiaraju figure.

Keywords: education, invisibility, Mbya-Guarani, myth.

\section{Invisibilidade}

A invisibilidade corresponde ao estado do que é invisível, consistindo na característica de um objeto não ser visível. Nos casos humanos remete à inexistência ou ao fato de a luz visível não ser absorvida nem refletida, como explorado nos filmes de ficção científica. Socialmente a invisibilidade acarreta um vasto conjunto de formas de exclusão e/ou discriminação por vezes escamoteadas que gravitam em torno de produção de percepções "equivocadas e interessadas" que objetivam conduzir a negativas de reconhecimento da diferença cultural. Trata-se da produção de imaginários que idealizam e celebram determinadas formas de ser percebidos e enraizados através de aprendizados partilhados, que rejeitam a dinâmica cultural e produzem assimetrias equivalentes a um não existir como correlato.

A produção de uma imagem/representação que se distancia da dupla imagem/referência que atua no real, enquanto diferença narrada, empurra para o terreno de estereótipo as reflexões sobre o outramento e seu exercício. Bhabha (1998, p. 65) nos chama atenção de que o conceito de diferença cultural é o solo comum e o território perdido dos debates contemporâneos:

Isto porque todos eles reconhecem que o problema da interação cultural só emerge nas fronteiras significatórias das culturas, onde significados e valores são (mal) lidos ou signos são apropriados de maneira equivocada. A cultura só emerge como um problema ou como uma problemática, no ponto em que há uma perda de significado na contestação e articulação da vida cotidiana entre classes, gêneros, raças e nações.

As práticas discursivas que reiteram diversidades sem o reconhecimento da diferença, como corolário dessa exclusão, reificam uma diversidade que se plasma no processo de invisibilização, conforme apresentaremos ao longo deste texto ao abordar as relações entre mito, diversidade cultural e educação, 
através da análise de representações do passado guarani no Rio Grande do Sul. Porém, antes de abordar essa circularidade narrativa é importante efetuar algumas observações sobre a visão como norteadora da percepção, por sua vez relativa à observação, e a questão da invisibilidade, analisadas por Ingold (2008, p. 7), para quem:

O caminho visual para a verdade objetiva é, ao que parece, pavimentado de ilusões. Precisamente porque a visão produz um conhecimento que é indireto, baseado na conjectura dos dados limitados disponíveis na luz, ela nunca poderá ser nada mais que provisória, aberta a futuros testes e à possibilidade de refutação empírica.

Nesse sentido, a própria ideia da representação visual como critério associado à objetividade na tradição ocidental é contestada pelo autor, para quem o exercício do olhar é inseparável da complexidade do movimento humano:

Longe de começar como radiação incidente e terminar como uma imagem mental, o processo da visão consiste em um processo interminável, um engajamento de mão dupla entre o perceptor e seu ambiente. É isso que queremos dizer quando falamos de visão, coloquialmente, como "olhar" ou "observar". (Ingold, 2008, p. 12).

A invisibilidade para o autor decorre da inexistência de reciprocidade visual e não da ausência de luz. Nesse sentido, ele equipara a invisibilidade percebida à perda de consciência de si enquanto imagem/representação. O processo de invisibilização para Ingold (2008, p. 34) associa esvanecimento de memória da imagem individual à percepção do outro:

Assim, sua visibilidade, sua identidade, de fato a sua própria existência como uma pessoa, é confirmada na visão dos outros. Em circunstâncias normais, ver outra pessoa é saber que você pode ser visto por ela, ver um lugar é saber que você pode, em princípio, ser visto lá por alguém. Mas, quando a outra pessoa é cega, a reciprocidade da visão se rompe.

Os processos são de alguma forma correlatos e o que entendemos por invisibilidade e, mais além, reconhecimento da alteridade indígena passa por essa tensão entre a auto e a exorreferência, perceptível nas narrativas no campo da educação patrimonial na região das Missões, estado do Rio Grande do Sul, 
e, mais recentemente, na produção do Coletivo Mbya-Guarani de Cinema, ligado à ONG Vídeo nas Aldeias.

Uma rápida análise de alguns textos literários do século XIX, concomitantes com o projeto de formação da nação no Brasil, nos mostra o índio romântico de José de Alencar, personificado na Iracema dos lábios de mel, entre outros. São imagens que ecoam no imaginário nacional em formação, conforme apontam Ortiz (1985); Schwarcz (1993, 2003) e Carvalho (2003). Igualmente o percurso mítico do personagem histórico Sepé Tiaraju se relaciona à perspectiva de invisibilidade guarani e mais além, da invisibilidade indígena, no Rio Grande do Sul.

\section{Sepé Tiaraju: 0 índio que os gaúchos querem viver}

Discorrer sobre o índio Sepé Tiaraju no contexto desta reflexão sobre a invisibilidade indígena no Rio Grande do Sul se justifica pela necessidade de relacionar a resistência à inclusão social, com algumas visões que se projetam historicamente sobre a dificuldade de convivência com a polêmica questão da presença indígena no estado e que se traduzem na dinâmica da vivência desse mito. Para Roland Barthes (2001, p. 131), o mito é uma fala, um sistema de comunicação, uma mensagem.

Pensar sobre Sepé Tiaraju remete às relações míticas que se estabelecem com o passado histórico no Rio Grande do Sul e a diversidade de formas pelas quais esse passado alimenta o imaginário gaúcho. O fascínio exercido por Sepé Tiaraju está no poder de significar o presente de quem o utiliza, transformando as identificações com o passado interpretado das Missões em pertencimentos à sua figura lendária, presentificada nos interesses e sentimentos de quem os aciona. Para entendê-lo como mito devemos nos reportar a esse passado colonial.

Durante os séculos XVII e XVIII, no noroeste do território onde atualmente se localiza o Rio Grande do Sul, habitantes originários guarani e os padres da Companhia de Jesus, representantes da coroa espanhola na América, protagonizaram a experiência missioneira platina. A polêmica experiência das Missões, conforme Meliá (1986), correspondeu sob o ponto de vista da integração colonial dos territórios e de seus habitantes ao aproveitamento do modo de ser dos habitantes originários guarani aos objetivos coloniais de 
catequização/ cristianização, através da construção das Reduções e, posteriormente, das Missões.

Os Trinta Povos das Missões foram fundados ao longo da Província Jesuítica do Paraguai, abrangendo o correspondente aos territórios atuais do noroeste do Rio Grande do Sul e parte do Paraná, Argentina e Paraguai. No Rio Grande do Sul, a construção das Missões pode ser pensada em dois momentos: o primeiro, iniciado com a fundação de São Nicolau do Piratini pelo Pe. Roque Gonzáles, em 1626, e que perdura até 1640 com a destruição dos povoados em virtude da atuação dos bandeirantes portugueses. O segundo momento (1682-1756) é o correspondente à construção dos Sete Povos das Missões: São Borja, São Luiz Gonzaga, São Nicolau, São Lourenço Mártir, São Miguel, São João Batista e Santo Ângelo.

Esse segundo momento pode ser pensado, no contexto dos Trinta Povos, como marco da expansão das fronteiras da coroa espanhola em oposição à atuação lusitana. Tal contexto se modifica com a desestruturação dos Sete Povos das Missões em virtude da Guerra Guaranítica (1754-1756). Nessa ocasião, como nos mostra Quevedo (2000), os Guarani missioneiros lutaram contra os exércitos unidos das duas coroas, se opondo à troca acordada entre as mesmas, no Tratado de Madri (1750), da Colônia do Santíssimo Sacramento, pertencente a Portugal, pelos Sete Povos das Missões, possessão da Espanha.

Nessa disputa, que culminou com a troca desses territórios entre as duas coroas e o processo de integração das Missões às possessões lusas, a historiografia, a literatura regionalista e a memória popular destacam a atuação de Sepé Tiaraju, comandante das tropas missioneiras, morto em 7 de fevereiro de 1756, pelos exércitos coloniais luso-hispânicos, nas escaramuças que antecederam a Batalha de Caiboaté (10/02/1756). Esta culminou com o massacre de cerca de 1500 índios e a derrota dos Guarani missioneiros frente ao exército luso-hispânico. A Sepé Tiaraju se atribui a expressão “esta terra tem dono”, referência atávica conhecida como o grito de Sepé, frequentemente percebida em representações que remetem à bravura dos gaúchos, que se representam como seus descendentes.

As menções a Sepé Tiaraju iniciaram no século XVIII, com o a publicação em 1769 do poema O Uraguai de Basílio da Gama (2002). O escritor regionalista João Simões Lopes Neto (2000) em 1913 apresenta a atuação de Sepé Tiaraju e sua santificação popular no poema $O$ lunar de Sepé e em São Sepé. A importância antropológica dessas referências a Sepé Tiaraju está 
na popularização de sua imagem através de uma linguagem regionalista. Elementos de O lunar de Sepé e da Lenda de São Sepé permanecem sendo utilizados na atualidade. Podemos observar tais referências na produção de representações tendentes a homenagear o herói. Elas se relacionam à necessidade de perpetuar a memória de sua atuação e a tomadas de posição sobre o momento que Sepé protagonizou, através das relações que indivíduos e grupos estabelecem com seu mito.

Atualmente, no Rio Grande do Sul, Sepé Tiaraju se constitui em uma das figuras históricas a que mais se alude, mesmo em zonas distantes da região missioneira. É provável que essas referências, via atualização de seu mito, sejam mais frequentes do que as alusões ao general Bento Gonçalves da Silva, proclamador da república rio-grandense, expoente maior da Revolução Farroupilha (1835-1845), referente para a exaltação do gaúcho como mito. Efetuamos a comparação, pois esses personagens sintetizam dois momentos históricos acionados na elaboração de identidades presentes a partir do passado, no estado do Rio Grande do Sul, conforme menciona Oliven (2006).

A menção ao herói farroupilha é compreensível a partir da lógica de construção da figura do gaúcho como tipo característico a ser cultuado - como uma expressão do folclore no Rio Grande do Sul. As constantes referências a Sepé Tiaraju põem em relevo o seu valor simbólico na construção das identidades regionais sulinas. Porém, se por um lado o gauchismo integra sua figura aos seus discursos, designando-o como "primeiro caudilho rio-grandense", "fundador de uma genealogia de bravos”, por outro lado há disputas pelo poder de nomeá-lo como "bandeira" de transformações sociais no estado.

Há também monumentos que representam sua figura, narrativas tradicionais que o santificam e o espetáculo Som e luz encenado em São Miguel das Missões, que o apresenta como herói. Há a proposta de sua canonização por uma parte da Igreja Católica, além de sua referência, em 2003, nos conflitos de terra na região de São Gabriel (Sepé Tiaraju foi morto em território do atual município). Nesse episódio Sepé foi mencionado e disputado como símbolo tanto pelo Movimento dos Sem Terra (MST), que batizou sua marcha com o nome de "Marcha Sepé Tiaraju”, conforme Göergen (2004), quanto pelos ruralistas da região, que denominaram sua atuação com o slogan "alerta: esta terra tem dono".

Em 2005, antecedendo as comemorações relativas aos 250 anos da morte de Sepé Tiaraju, realizadas em 2006, em São Gabriel, foi proposto na Câmara

Horizontes Antropológicos, Porto Alegre, ano 21, n. 44, p. 201-227, jul./dez. 2015 
dos Deputados o projeto de lei 5.516 que: "inscreve o nome de Sepé Tiaraju no Livro dos Heróis da Pátria” (Brasil, 2009). A lei institui Sepé Tiaraju como herói brasileiro. Igualmente, na Assembleia Legislativa do Estado do Rio Grande do Sul a lei 12.366 foi aprovada por unanimidade e sancionada no dia 3 de novembro de 2005 pelo governador Germano Rigotto. O texto da lei declara Sepé Tiaraju como "herói guarani missioneiro rio-grandense”, instituindo o dia de sua morte, 7 de fevereiro, como data oficial de eventos do estado (Rio Grande do Sul, 2005).

O surgimento das duas leis relativas à instituição de Sepé Tiaraju como herói nacional e regional remetem a profundas modificações nas identidades liminares do índio guarani missioneiro Sepé Tiaraju: nem índio guarani, nem português, nem espanhol, tampouco brasileiro. Sua liminaridade passa a receber um novo tratamento, já que Sepé Tiaraju, por força de lei adquire um caráter de brasilidade, tendo sua gauchidade reforçada. Sua figura indígena mitificada passa a ser integrada como etnia concorrente na construção das identidades regionais e nacionais, a partir de sua definitiva celebração como herói, num contexto discursado como "multicultural".

Ao ser erigido como herói gaúcho e brasileiro, Sepé é exaltado como símbolo da luta pela terra. Suas identidades liminares de Guarani missioneiro não estão mais sendo questionadas, bem como o caráter de sua luta. Conforme Lévi-Strauss (1996), o mito objetiva resolver as contradições entre o passado e o presente. No caso de Sepé Tiaraju e do passado missioneiro, suas apropriações, nesse caleidoscópio de significações, como disse igualmente LéviStrauss (1997), "servem para pensar” sobre as relações que estabelecemos com o passado e sobre nossas identidades presentes.

Do ponto de vista da invisibilidade e da opacidade da questão indígena no Rio Grande do Sul, conforme destacam Oliven (2006) e Souza (1998, 2009), frente ao contingente dos que habitam o estado, uma das expressões mais significativas na vivência do mito de Sepé Tiaraju e de sua aproximação/ distanciamento dos Guarani contemporâneos é o espetáculo Som e luz. Este é apresentado todas as noites no Sítio Arqueológico de São Miguel Arcanjo, declarado pela Unesco como Patrimônio da Humanidade, localizado em São Miguel das Missões.

Trata-se de uma narrativa épica elaborada com o intuito de abordar o passado missioneiro. Podemos caracterizá-lo como o teatro histórico que propõe ao público descobrir não apenas os personagens, mas também um cenário das 
Missões durante os séculos XVII e XVIII. O espetáculo estabelece a identificação entre o passado e o presente através de sua exaltação como proposta turística encarregada de popularizar os sujeitos históricos, o espaço de São Miguel e enaltecer o patrimônio missioneiro, ao produzir mitos a serem cultuados dentro e fora da região das Missões.

O espetáculo propicia um retorno ao passado. Configura-se em importante disseminador da imagem de Sepé Tiaraju, ao apresentar a visão do passado missioneiro, através de uma narrativa teatralizada calcada na expressão dos elementos naturais e materiais que compõem o cenário da ruína reconhecida como patrimônio na atualidade, enquanto testemunho material surgido durante a experiência missioneira passada.

A narrativa da história das Missões é elaborada a partir da apresentação de seus protagonistas principais: a terra e a igreja e alguns sujeitos relacionados ao passado dos Sete Povos chamados a dar seu depoimento, contando "o que realmente houve” e "o porquê” de, na atualidade, apenas existirem vestígios (as ruínas), testemunhos daqueles tempos.

É à memória de Sepé Tiaraju que o espetáculo é dedicado ao enfatizar sua luta pela terra das Missões e as razões de sua morte em prol da justiça, sendo apresentado como um cacique-corregedor da Redução de São Miguel com poder de decisão e influência sobre seus pares guarani. O modelo de virtudes cristãs que encerra, em razão de sua formação jesuítica, se insurge contra a notícia da disposição do Tratado de Madri (1750) de trocar os Sete Povos das Missões pela Colônia do Sacramento. É nessa conjuntura que ocorre sua célebre manifestação: "Esta terra tem dono. Ela nos foi dada por Deus e por São Miguel.”

Frente à irredutibilidade da decisão da troca das terras missioneiras, Sepé Tiaraju passa a ser apresentado como seu principal defensor, opondo-se à posição dos próprios padres jesuítas de entregar os Sete Povos, passando a lutar contra os exércitos unidos das duas coroas. A representação de sua figura abrange conjuntamente o Sepé guerreiro e o líder político, um estadista indígena que não se dobra aos caprichos dos comandantes “estrangeiros” ibéricos, representados como usurpadores, invasores, na sua ótica nativista.

Em contrapartida, Sepé é percebido pelos luso-hispânicos como um insolente, bárbaro e guerreiro experimentado no comando da resistência guarani. As oposições entre o universo natural atribuído a Sepé e as distorções da percepção dos interesses e da visão de justiça das partes envolvidas se 
configuram em metáforas do passado missioneiro e dos elementos escolhidos para representá-lo de forma evolutiva e maniqueísta: a passagem do universo natural guarani à construção de uma civilização do bem, sacralizada por Deus (as Missões) em oposição ao mal (os exércitos unidos das coroas ibéricas) responsáveis por sua desagregação.

A morte de Sepé Tiaraju é apresentada pela recusa do índio de parar de lutar: "eu quero viver", evitando aceitar o seu fim, sendo ferido por uma lança de origem espanhola e um tiro "de misericórdia" alardeado pelo comandante do exército português. Essa dupla morte ilustra a superação dos inúmeros desacordos que caracterizaram a atuação da comissão demarcatória de limites. O espetáculo é finalizado com a troca de comando das tropas missioneiras (que passam a ser dirigidas por Nicolau Languiru) após a morte de Sepé e a tomada das Missões a partir da invasão de São Miguel. Nesse momento, adquire um tom de "acerto de contas com o passado missioneiro" e o trabalha em termos de memória social, objetivando construir uma lição a partir dessa experiência passada, enaltecendo a terra como valor supremo e a liberdade acima de todas as coisas: "Terra que circula em nossos corpos, é teu o nosso trabalho. Ventos claros, rios prateados, independência natural, esposa comum. Liberdade. É por ti a nossa luta, e toda a nossa lealdade.” (texto do espetáculo Som e luz).

Ao ser representado como defensor da liberdade mesclada à ideia de democracia e de telurismo aguerrido na defesa do "pago", bem como da terra como um valor sagrado e preponderante, Sepé tem sua imagem de índio real subjugada por sua representação romântica. O espetáculo aproveita essa multiplicidade de representações acerca das Missões e de Sepé Tiaraju, acolhidas do trabalho de Clóvis Lugon (1977) - A república comunista cristã dos guaranis - com relação à construção do modelo comunitário das reduções, produzido pelo espetáculo, bem como a própria utilização do poema $O$ Uraguai de Basílio da Gama (2002), na composição da figura heroica do índio romântico Sepé Tiaraju.

A recepção dessas representações e sua reelaboração pelo espetáculo se inserem numa perspectiva educacional de circulação e (re)semantização de análises do passado para a produção de um imaginário, através de uma linguagem popular que objetiva alcançar a maior parte do público, composto, sobretudo, pelas escolas de todo estado que vêm assistir ao espetáculo como parte de suas atividades letivas. A construção desse imaginário favorável se plasma 
na elaboração do mito de Sepé Tiaraju como pedagogia da boa história, lição a ser introjetada e entendida como "a verdadeira história das Missões", que é situacionalmente aprendida (Ingold, 2010) pelos espectadores e levada como bagagem de sua visita a São Miguel das Missões.

Ante essa construção épica, a recepção do Som e luz pelo público estampa as contradições entre o passado glorioso representado no espaço das ruínas de São Miguel e o seu status presente através da impossibilidade de percepção das transformações ocorridas na região e de seus atores, especialmente com relação aos Mbya-Guarani que vivem na Tekoa Ko'enju, a $30 \mathrm{~km}$ da cidade de São Miguel das Missões, e que vendem artesanato durante o dia, no Sítio Arqueológico. O Som e luz, nesse sentido, ao construir e caracterizar de forma romântica Sepé Tiaraju, o distancia irremediavelmente desses Mbya-Guarani que vivem na região.

Os turistas e estudantes ${ }^{1}$ presentes não os reconhecem como "descendentes” de Sepé Tiaraju ao se depararem com suas figuras de aparência pobre, quando param para olhar o artesanato, após visitas guiadas ou percursos individuais que fazem no espaço do sítio. Quando os encontram em torno do Museu das Missões, expondo suas peças, demonstram-se curiosos para saber sobre sua etnia, sobre o quanto ainda "preservam" dos costumes e o quanto falam de sua língua. Adolescentes que aprenderam em algum livro de história ou literatura uma ou outra palavra em guarani aproximam-se para repetir o vocábulo e tentar estabelecer algum diálogo. Riem e usam de termos pejorativos, entendendo que os índios não compreendem o que querem fazer. Os Mbya em geral ignoram ou fazem comentários irônicos, em guarani, permanecendo com as cabeças baixas e olhares vagos, em uma performance que faz com que os visitantes acreditem que eles não sabem falar. $\mathrm{O}$ fato é que não desejam responder e não veem sentido naquilo que dizem os estudantes.

\footnotetext{
1 A região recebe um grande número de turistas vindos dos mais diversos lugares, bem como estudantes de diversos níveis de ensino, em viagens de estudos, que chegam à região em busca do "nativo intacto", tal como descreve Grünewald (2003). Dentre os estudantes, chama atenção crianças matriculadas no ensino fundamental, que estudam a história da região e do estado do Rio Grande do Sul nas aulas de Estudos Sociais. A visitação ao Sítio Arqueológico de São Miguel Arcanjo é parte dos currículos das escolas e os estudantes chegam ao sítio com uma ideia já elaborada sobre como as reduções operavam e do quanto significavam uma espécie de progresso para a vida indígena, proporcionada pela Companhia de Jesus. É marcante a imagem dos Guarani enquanto um povo do passado, exótico, dos quais se deseja saber o quanto caçam, pescam, se usam arco e flecha, o que vestem e do que se alimentam.
}

Horizontes Antropológicos, Porto Alegre, ano 21, n. 44, p. 201-227, jul./dez. 2015 
A eficácia simbólica do Som e luz na construção concorrente das identidades no Rio Grande do Sul é relativa à Sepé como o primeiro gaúcho rio-grandense. É, pois, excludente da figura do índio real, presente em São Miguel. Assim, a figura do índio enquanto identidade concorrente apenas é aceita e integrada como simulacro, para elaboração da imagem do gaúcho, nos valores de bravura e valentia, sendo negada em relação aos Mbya-Guarani que lá estão. Ramos (1995, p. 11) exemplifica a produção do simulacro:

Criam-se estruturas quase-cartoriais destinadas a gerir os recursos muitas vezes vultosos que permitam produzir e manter esse simulacro que é o índio hiper-real, dependente, sofredor, vítima do sistema, inocente das mazelas burguesas, íntegro em suas ações e intenções e de preferência exótico. Os índios assim criados são como clones de fantasia, feitos a imagem de que os brancos gostariam de ser eles mesmos. Pairando acima e além do real o modelo de índio passa a existir como que numa quarta dimensão, instituindo uma entidade ontológica de terceiro grau.

No entanto, o passado missioneiro vivificado nas apropriações efetuadas das narrativas já referidas, apesar de ocorrer no presente, dele se afasta em razão de sua perspectiva performática e apologética. A produção do imaginário missioneiro contrasta com a pobreza material dos Mbya-Guarani de São Miguel uma pobreza que é também externada pelos turistas e estudantes, em relação ao passado missioneiro, cujo espaço continuam a ocupar. Os Guarani ali presentes não são percebidos sequer como índios (Brum, 2009, p. 26). Nesse sentido, um dos processos de aprendizagem vivenciados por aqueles que assistem ao espetáculo reside na afirmação da invisibilidade indígena dos Mbya-Guarani ali presentes ao valorizar o mito de Sepé Tiaraju em sua idealidade de atuação no passado missioneiro como um índio de feições brancas, frente à negação da dinâmica cultural dos Guarani reforçada pelo espetáculo de Som e luz.

Nesse cenário, iniciativas recentes do Instituto de Patrimônio Histórico e Artístico Nacional (Iphan), em diálogo com grupos guarani, buscam elaborar políticas de gestão do patrimônio ${ }^{2}$ que valorizem o protagonismo

\footnotetext{
Tais ações concentram-se no Programa Nacional de Patrimônio Imaterial, através do qual o Iphan desenvolve projetos de identificação, reconhecimento, salvaguarda e promoção da dimensão imaterial do patrimônio cultural. Integram este programa o “Inventário Nacional de Referências Culturais” (INRC), que documenta bens culturais e o "Registro dos Bens de Natureza Imaterial” (RBNI).
}

Horizontes Antropológicos, Porto Alegre, ano 21, n. 44, p. 201-227, jul./dez. 2015 
indígena nesses espaços. Através dessas ações, o Sítio Arqueológico de São Miguel Arcanjo passou a ser reconhecido pelo Iphan, em dezembro de 2014, como lugar de referência mbya-guarani. Tal processo resulta do "Inventário Nacional de Referências Culturais Comunidade Mbya-Guarani”, iniciado em São Miguel das Missões no ano de 2004 sob a coordenação do antropólogo e etnoarqueólogo José Otavio Catafesto de Souza, da Universidade Federal do Rio Grande do Sul. O objetivo dessa metodologia, desenvolvida pelo Instituto do Patrimônio Histórico e Artístico Nacional, é documentar bens culturais em parceria com grupos e comunidades que compartilham dessas referências. No caso da população Mbya, o estudo começou na Tekoá Ko'enju e se estendeu para outros lugares do Rio Grande do Sul, tais como o Caaró (em Caibaté); Terra Indígena Salto do Jacuí (em Salto do Jacuí); Terra Indígena Lomba do Pinheiro (em Porto Alegre) e Terra Indígena Capivari (em Palmares do Sul). Deste trabalho, resultou uma publicação denominada Tava Mirĩ São Miguel Arcanjo, Sagrada Aldeia de Pedra: os Mbyá-Guarani nas Missões, a qual traz o Sítio Arqueológico de São Miguel Arcanjo como um espaço sagrado para os mbya: Tava Mirĩ ou "sagrada aldeia de pedra".

Somando-se a esse trabalho está a parceria desenvolvida entre o Iphan e a ONG Vídeo nas Aldeias, para a realização do documentário Tava: a casa de pedra (2011), uma produção realizada junto ao Coletivo Mbya-Guarani de Cinema, cuja maioria dos membros vivem na Tekoa Ko 'enju e fazem parte de famílias que vendem artesanato no Sítio Arqueológico de São Miguel Arcanjo. A produção do filme foi feita por Ariel Ortega, ${ }^{3}$ Patrícia Ferreira, ${ }^{4}$ Ernesto de Carvalho ${ }^{5}$ e Vincent Carelli. ${ }^{6}$ A equipe percorreu diversas aldeias, localizadas nos estados brasileiros do Rio Grande do Sul, São Paulo e Rio de Janeiro, além de aldeias situadas em território argentino, bem como o cotidiano de visitação e venda de artesanato no Sítio Arqueológico de São Miguel Arcanjo, no Rio Grande do Sul e San Ignacio, em Misiones, Argentina. $\mathrm{O}$ objetivo foi ouvir pessoas guarani que vivem em diferentes lugares do país

\footnotetext{
Cineasta do Coletivo Mbya-Guarani de Cinema/Vídeo nas Aldeias e cacique da Tekoa Ko 'enju.

4 Cineasta do Coletivo Mbya-Guarani de Cinema/Vídeo nas Aldeias e professora da Escola Igíneo Romeu Ko’enju, localizada na Tekoá Ko'enju.

5 Antropólogo, documentarista e fotógrafo. Coordenador de oficinas de formação e edição de vídeo no âmbito da Vídeo nas Aldeias.

6 Secretario executivo da ONG Vídeo nas Aldeias em Olinda, formador de realizadores indígenas e produtor de seus filmes.
} 
e fora do país, mas em regiões que foram espaço de Missões, sobre a importância das ruínas na vida social guarani. Privilegiou-se o diálogo com anciãos de prestígio, vinculados às parentelas das quais os realizadores indígenas fazem parte, bem como com lideranças guarani mais jovens, envolvidas nos diálogos acerca dos processos de demarcação de terras no contexto brasileiro.

A diferença primordial entre esses dois trabalhos, o documentário e o livro do INRC Comunidade Mbya-Guarani, encontra-se nas ideias de Tava e Tava Mirim. ${ }^{7}$ Distinção, grosso modo, entre uma casa de pedra e uma casa de pedra sagrada. Diferenças com relação à sacralidade do lugar estão relacionadas às distintas versões que os Mbya atribuem para as casas de pedra que hoje são patrimônios nacionais e patrimônios da humanidade. Segundo Patrícia, há descendentes de Mbya que fugiram das Reduções e que carregam consigo, nas histórias contadas de geração em geração, que as “ruínas” não são tava sagradas. De outro lado, há ainda descendentes de Mbya reduzidos que aprenderam que os jesuítas eram Nhanderu Mirim, divindades. E estas pessoas consideram as "ruínas” Tava Mirim, um lugar sagrado.

As distintas interpretações a esse respeito foram debatidas na mesa-redonda "Versões de História”, realizada no II Seminário Internacional de Educação Indígena, na Universidade Federal de Santa Maria. Na oportunidade, Patrícia Ferreira, Aldo Ferreira e Ralf Ortega, do Coletivo Mbya-Guarani de Cinema, falaram sobre o documentário e sobre os diferentes sentidos que os Guarani das aldeias visitadas atribuem às ruínas de São Miguel Arcanjo. De outro lado, José Otávio Catafesto de Souza também falou sobre os resultados do relatório feito para o Iphan e sobre as concepções divergentes em torno da sacralidade do local. Para o pesquisador e sua equipe, há que se considerar a complexidade desse tipo de definição na cosmologia mbya-guarani, de modo que a forma mais adequada de se pensar sobre o sítio arqueológico seria nos termos de tava ta'anga. Essa definição insere as significações acerca das tava nas ideias de imagens terrenas ( $a$ 'anga ou ta'anga), elementos importantes da cosmovisão guarani. Nas narrativas de criação do mundo é mencionado que as criações divinas encontradas nesta terra são apenas imagens das criações verdadeiras que se encontram na morada de Nhamandu Tenonde, o deus que

\footnotetext{
7 Utilizamos a grafia Mirim por ser esta a escrita utilizada pelos interlocutores indígenas, ligados ao Coletivo Mbya-Guarani de Cinema. Em outros momentos do texto, observa-se a grafia de Mirĩ, que é mantida por remeter a categorias utilizadas pelos autores que estão sendo citados nesses espaços.
}

Horizontes Antropológicos, Porto Alegre, ano 21, n. 44, p. 201-227, jul./dez. 2015 
as criou. Nessa perspectiva, defendida pela equipe de pesquisa do Inventário Nacional de Referências Culturais, as ruínas são imagens terrenas (ta'anga), dos ambá ou moradas divinas, que são Tava Mirim - casas de pedra - no mundo dos deuses. Assim, o que se vê no sítio arqueológico pode ser lido, por alguns Guarani, somente como tava (sem atribuição de lugar sagrado) por ser uma imagem de Tava Mirim, a verdadeira casa de pedra sagrada, que não se encontra neste mundo. ${ }^{8}$

De todos os modos, guardando as devidas especificidades, os dois trabalhos apontam para a região e o Sítio Arqueológico de São Miguel Arcanjo como lugar de grande importância para os Guarani. Isso porque que mesmo aqueles Mbya que não consideram esse espaço como sagrado mencionam as ruínas como parte dos espaços a serem percorridos na realização do jeguata - a caminhada sagrada, mencionada pelos Mbya como um ensinamento que perpassa de geração em geração, que os mantém unidos, solidificando laços de parentesco. Essa mobilidade une não somente espaços territoriais, mas cosmológicos.

\section{Invisíveis e estrangeiros: a invisibilidade questionada pelo Coletivo Mbya-Guarani de Cinema}

O Coletivo Mbya-Guarani de Cinema é um dos coletivos formados a partir da atuação da Vídeo nas Aldeias, uma organização não governamental que atua na execução de projetos de produção audiovisual com populações indígenas, no Brasil. O primeiro filme realizado pelo coletivo foi Mokoi Tekoá Petei Jeguatá - Duas aldeias, uma caminhada (2011), o qual apresentava o cotidiano das aldeias Anhetenguá, também conhecida como Lomba do Pinheiro, em Porto Alegre, e Ko'enju, em São Miguel das Missões. Realizado entre 2007 e 2008, contava com cineastas mbya-guarani de ambas as aldeias, tendo muitas de suas imagens condensadas em um curta denominado Nós e a cidade (2009), com uma narrativa que foca especificamente na relação com o urbano, através das vendas de artesanato, tanto no centro de Porto Alegre quanto no Museu das Missões, em São Miguel.

8 Ver também Souza e Morinico (2012).

Horizontes Antropológicos, Porto Alegre, ano 21, n. 44, p. 201-227, jul./dez. 2015 
Atualmente o coletivo conta com oito membros e as oficinas de vídeo têm sido realizadas na Tekoa Ko'enju, onde vive a maioria dos cineastas que o integram: Ariel Ortega, Patrícia Ferreira, Leonardo Ortega, Aldo Ferreira e Ralf Ortega. Todos os integrantes são jovens, na faixa etária entre 17 e 28 anos de idade, e possuem relações de parentesco e/ou aliança. Pertencem a parentelas de prestígio reconhecido, são netos de xamãs (karaí e kunhã karai) ou anciãos bastante respeitados (xeramoin e xejary kuery). Alguns ocupam também lugares de liderança e possuem parentes próximos que são reconhecidos líderes políticos em aldeias guarani do Rio Grande do Sul e da província de Misiones, na Argentina. A maioria concluiu o ensino fundamental e parou de estudar, sendo que dois concluíram o ensino médio.

A Tekoa Ko 'enju, onde vivem, denominada também de Aldeia Alvorecer (tradução para a língua portuguesa), possui uma extensão de 236 hectares de terras, compradas pelo governo do estado do Rio Grande do Sul no sul do Brasil no início dos anos 2000 e destinadas à algumas famílias mbya-guarani que haviam estabelecido acampamento no município de São Miguel das Missões, próximo à chamada Fonte Missioneira - uma fonte de água que, provavelmente, abastecia a antiga Redução de São Miguel Arcanjo.

O acampamento, como tantos que são erguidos no Rio Grande do Sul e em outros estados brasileiros, ${ }^{9}$ não era o primeiro acampamento guarani na região de São Miguel e demarcava a importância desse espaço para as redes de mobilidade desse povo. A decisão do governo do Estado em comprar terras para "assentar" as famílias esteve relacionada a propiciar um espaço mais adequado às mesmas. A área adquirida localiza-se a $30 \mathrm{~km}$ do antigo acampamento, abriga atualmente cerca de 200 pessoas e, segundo dados do Instituto Sócio-Ambiental, passou a ser reconhecida como Reserva Indígena Inhacapetum, ${ }^{10}$ através do decreto 40.483 , publicado em 30 de novembro de 2000 (Rio Grande do Sul, 2000).

\footnotetext{
9 Historicamente, os acampamentos indígenas no sul do Brasil são erguidos, em sua maioria, às margens de rodovias, em áreas sob a responsabilidade dos departamentos de trânsito - espaços que separam as rodovias das propriedades privadas. Essa apropriação do espaço visa retomar territórios e reivindicar a demarcação dos mesmos, junto ao governo brasileiro. Situação semelhante acontece em outros estados do Brasil, como no Mato Grosso do Sul, no centro-oeste do país, com os chamados assentamentos de corredor (Pereira, 2006).

${ }^{10}$ Referência a um rio, de mesmo nome, próximo a essas terras.
} 
A presença guarani nas vendas de artesanato junto ao Museu das Missões são imagens correntes nos filmes produzidos pelo Coletivo Mbya-Guarani de Cinema. O comércio das peças é narrado como um produto da colonização e da constituição do Estado brasileiro, que levaram à destituição de terras guarani, ao esgotamento ecológico e criaram a necessidade de vender artesanato. Discorrendo sobre a produção da invisibilidade, em Desterro guarani (2011), o narrador Ariel Ortega elabora uma reflexão sobre territorialidade de seu povo e os modos através dos quais as terras que habitavam foram sendo tomadas pela lógica da propriedade privada. Narra como os acampamentos à beira de rodovias foram surgindo e como os Guarani passaram a demandar processos de demarcação de terras junto à União. Chega assim à conclusão de que com o passar dos anos os Guarani, além de invisíveis, tornaram-se estrangeiros, referindo-se ao modo como fronteiras nacionais foram postas na dinâmica de mobilidade mbya, especialmente entre Brasil e Argentina.

As reflexões trazidas pelos realizadores dos filmes demonstram o que Pacheco de Oliveira (1998) descreve como territorialização. Segundo o autor, a presença colonial é um fato histórico que instaura uma nova relação da sociedade com o território, deflagrando transformações em distintos níveis culturais. Assim, a noção de territorialização define-se como

um processo de reorganização social que implica: 1) a criação de uma nova unidade sociocultural mediante o estabelecimento de uma identidade étnica diferenciadora; 2) a constituição de mecanismos políticos especializados; 3) a redefinição do controle social sobre os recursos ambientais; 4) a reelaboração da cultura e da relação com o passado. (Pacheco de Oliveira, 1998, p. 55, grifo do autor).

O desenho das reduções da América espanhola é citado por Pacheco de Oliveira (1998) como um objeto político-administrativo que, via um processo de territorialização, transformou-se em uma coletividade organizada, formulou uma identidade própria, instituiu tomadas de decisões e de representações, bem como reestruturou formas culturais, as quais incluem a relação com o meio ambiente e com o universo religioso. Para o autor, tal configuração demanda pensarmos nas formulações de Barth, no campo das teorias da etnicidade, acerca de processos de diferenciação e individualização que organizam o social. Nesse contexto, tanto afinidades culturais ou linguísticas como os vínculos afetivos e históricos que ligam os membros dessa unidade político-administrativa, tendem a ser retrabalhados pelos próprios sujeitos em um 
contexto histórico determinado, contrastados com características atribuídas aos membros de outras unidades, deflagrando um amplo processo de reorganização sociocultural.

No caso da interpretação do passado das reduções espanholas pelos Guarani que vivem na região das Missões, suas narrativas tendem a enfatizar que não descendem daqueles que viveram nas reduções, questionando sobretudo a ideia de que a evangelização teria acontecido por completo, tal como narrada pela história oficial, pelos guias de turismo e pelo espetáculo Som e luz. Há um esforço em mostrar que vivem e caminham por essas terras, mas que seus antepassados não adotaram a religião católica (Jesus, 2015). Ainda assim, trazem em seus filmes diferentes versões sobre a vida nas reduções e o lugar dos jesuítas no imaginário dos Guarani contemporâneos. Trata-se de uma forma de diferenciarem-se tanto dos não indígenas que vivem na região como de outros guarani, de outras aldeias, que localizam, por exemplo, a imagem do jesuíta como o herói desbravador (kesuita) que alcançou a perfeição espiritual (aguydje) e passou a viver na terra dos Nhanderu Mirim, divindades intermediárias, humanos que atingiram o estado de kandire ou imortalidade, por conta de sua perfeição/aguydje. Para os Guarani que vivem na região e que compõem o Coletivo Mbya-Guarani de Cinema, os jesuítas eram padres que trouxeram destruição e tristeza, iniciando o processo de destituição de suas terras.

Em Tava: a casa de pedra (2011), a narrativa fílmica inicia com imagens do enterro de uma kunhã karai ${ }^{11}{ }^{11}$ que vivia na aldeia do Salto do Jacuí. O caixão é levado por seus parentes e por um grupo de pessoas, dentre os quais muitos anciãos. O cortejo é acompanhado por música e os parentes próximos, principalmente, caminham fumando petyngua (cachimbo). Ao chegar na cova, a mulher mais velha, com seu petyngua, ${ }^{12}$ fala $^{13}$ aos demais: "Esta é a música que $N$ handeru ${ }^{14}$ nos dá para termos força.” O caixão é defumado

11 Mulher xamã.

12 Cachimbo.

13 Todas as falas serão aqui transcritas conforme a tradução dada pela equipe do Coletivo Mbya-Guarani de Cinema.

${ }^{14}$ Nhanderu é um termo traduzido como "nosso pai” e refere-se ao pai verdadeiro de cada Guarani, que juntamente com Nhandetxy, a “mãe verdadeira”, envia o nhe'é (duplo/alma), que habita o corpo da pessoa, a esta terra. Nas legendas do Coletivo Mbya-Guarani a expressão pode aparecer como Nhanderu, Deus ou Pai. Os Guarani possuem um pai criador, Nhanderu Tenonde, que criou sua companheira feminina (Nhandetxy Tenonde) e mais quatro casais de pais e mães verdadeiros, que enviam os nhe'é kuery (expressão que a antropologia convencionou traduzir como “almas-palavras”) a esta terra.

Horizontes Antropológicos, Porto Alegre, ano 21, n. 44, p. 201-227, jul./dez. 2015 
e a txedary ${ }^{15}$ diz que está falando com Nhanderu para que os que fiquem não morram de tristeza. Fala da alma pura e do corpo imperfeito, chamando Nhamandu, e lhe dizendo que aquela alma estava partindo desta terra.

Essa imagem aos poucos vai se fechando, surge a introdução e o logo do Vídeo nas Aldeias e então as cenas do sítio arqueológico: uma mulher tirando o pó da exposição das peças de arte sacra que ficam no interior do Museu das Missões; o chão externo sendo varrido; e artesanatos mbya sendo expostos ali, sobre um tecido. O enterro da kunhã karai é lembrado em outras passagens do filme, mas não está diretamente relacionado às narrativas expostas pelos entrevistados. Ainda assim, é crucial para a estratégia de legitimação posta pelos realizadores: não se está falando de preservação material, não se discute patrimônio ou turismo. Na base de toda a compreensão está um universo de entendimento cosmológico propriamente guarani: de almas puras, que habitam corpos imperfeitos e vivem de modo a tentar alcançar uma terra melhor, uma terra sagrada, cujo destino implica a passagem pelas casas de pedra, chamadas de tava.

Conforme se mencionou acima, as narrativas sobre as ruínas de São Miguel variam. Há quem afirme que são Tava Mirim e há quem discorde. Sepé Tiaraju, no entanto, é visto com glória, mas não a glória que o espetáculo Som e luz, o Movimento Tradicionalista Gaúcho e a Diocese lhe atribuem. Para os Guarani entrevistados, os jurua kuery (não indígenas) não entendem quem foi Sepé. Alguns, como Mariano Aguirre, afirmam que Sepé não morreu, como os não indígenas pensam, mas sim levou seu corpo para Yvy Mara $E y$, a Terra sem Mal. Nessas versões, Sepé teve um grande papel político, pois enganou os jesuítas, lutou por seu povo, foi bravo e, por saber viver e praticar o bem, alcançou a terra sagrada. Mariano é um dos principais interlocutores dos documentários elaborados pelo coletivo. Em Tava: a casa de pedra (2011) e Desterro guarani (2011) fala sobre esse seu entendimento acerca de Sepé Tiaraju e diz que as ruínas não são Tava Mirim, pois Tava Mirim localizam-se no espaço onde enxergamos os raios, não nesta terra. O Sr. Adolfo, xeramoin (avô, homem mais velho) que vive na aldeia de Varzinha, em Caará (RS), diz que a morte de Sepé foi comemorada pelos brancos como se nenhum Guarani

15 Anciã, avó.

Horizontes Antropológicos, Porto Alegre, ano 21, n. 44, p. 201-227, jul./dez. 2015 
mais restasse. O que não sabiam era que o $k a r a i^{16}$ e a $k u n h a ̃ ~ k a r a i^{17}$ que viviam ali conseguiram entrar por debaixo da terra, indo até o Paraguai, onde construíram uma tava. Augusto e Florentina, que vivem na aldeia Cantagalo, também dizem que ouviam contar que Sepé não morreu, apenas fingiu. No entanto, compreendem que os jesuítas eram mesmo Nhanderu Mirim, que deixaram essa tava na terra como um símbolo. Vieram para esta terra e seguiram para a Terra sem Mal, construindo outras tava.

No que concerne aos processos de produção dos filmes - desde a captação de imagens e entrevistas, perpassando os momentos em que essas gravações são assistidas pelas pessoas da aldeia, até o filme pronto apresentado em sessões específicas à comunidade - ficam bastante nítidas as reflexões nativas sobre os Guarani e as Missões. Trata-se de um processo educacional de reversão da invisibilidade guarani. Dominique Gallois e Vicent Carelli em um texto publicado em 1995, fizeram menção aos efeitos do trabalho do Vídeo nas Aldeias, ${ }^{18}$ até aquele momento:

Constata-se, em primeiro lugar, que o acesso ao vídeo amplia as possibilidades de comunicação, internas e externas, entre grupos indígenas. A experiência do projeto Vídeo nas Aldeias mostra que, quando colocados sob o controle dos índios, os registros em vídeo são principalmente utilizados em duas direções complementares: para preservar manifestações culturais próprias a cada etnia, selecionando-se aquelas que desejam transmitir às futuras gerações e difundir entre aldeias e povos diferentes; para testemunhar e divulgar ações empreendidas por cada comunidade para recuperar seus direitos territoriais e impor suas reivindicações. No entanto, a experiência também comprova que a apropriação do vídeo pelos povos indígenas extrapola a função instrumental da comunicação. Os resultados obtidos estão menos na maior circulação de informações entre os povos do que na forma inovadora como esses grupos se apropriam delas. Tecnicamente, o vídeo modifica substancialmente a produção e a transmissão de conhecimentos. Comparado com outros instrumentos de comunicação utilizados em programas de "resgate" cultural, a inovação que o vídeo representa tem uma dupla vantagem: sua apreciação passa pela imagem, sua apropriação é coletiva. (Gallois; Carelli, 1995, p. 63).

16 Xamã masculino.

17 Xamã feminino.

${ }^{18}$ Nesse período o Vídeo nas Aldeias integrava o Centro de Trabalho Indigenista (CTI). Atualmente configura-se em uma ONG independente.

Horizontes Antropológicos, Porto Alegre, ano 21, n. 44, p. 201-227, jul./dez. 2015 
Tais aspectos são constantemente acionados no trabalho desenvolvido pelo Coletivo Mbya-Guarani de Cinema. Os vídeos não são apenas modos de sistematizar saberes nativos, mas de aprender e refletir coletivamente sobre a história Mbya e sobre os modos como os não indígenas relacionam-se com o passado missioneiro. São oportunidades de perceber recorrências nas narrativas dos mais velhos, esclarecer dúvidas e comparar tais perspectivas com as experiências vividas - ações que extrapolam o trabalho do coletivo e que se disseminam no cotidiano da aldeia e nos eventos políticos nos quais se assiste e se conversa sobre esses filmes.

Tais elementos inserem-se no cotidiano social como formas de circulação de saberes nativos e embasam o diálogo com os não indígenas em muitos aspectos, especialmente no campo dos direitos territoriais. Mostrar os caminhos que produziram a invisibilidade guarani por meio da produção de documentários tem sido uma estratégia mbya para tornarem-se visíveis, e mais ainda: para legitimarem sua presença e suas reivindicações por demarcação de terras, na região das Missões.

Nesse processo, os filmes são tanto uma forma de disseminar a palavra dos mais velhos; de questionar o modo como a história oficial, os projetos turísticos e o espetáculo Som e luz narram o passado guarani, ou seja, um passado de catequização; de refletir sobre o impacto dessas representações no cotidiano das aldeias; e de colocar-se na imagem para dialogar com o Estado brasileiro, fazendo escolhas acerca do que se deve ou não mostrar. Tais escolhas demandam um longo processo de discussão na Tekoa, uma vez que a comunidade avalia as imagens que devem ou não ser inseridas, considerando tanto o impacto do filme para expectadores não indígenas como para outros Guarani. As decisões envolvem as narrativas que se quer transmitir, mas também as posturas que se deseja incentivar dentro das aldeias, tanto por parte dos jovens quanto por parte dos mais velhos.

Nesse contexto, no que tange às narrativas sobre o passado guarani nas reduções espanholas, os filmes enfatizam que não eram apenas povos guarani que viviam nesses espaços, e dedicam tempo significativo para as falas dos mais velhos sobre a religião guarani, no sentido de mostrar como a mesma diferencia-se da religião dos jesuítas. Também destacam a importância de mostrar a versão guarani da história, de estratégias de aproximação dos jesuítas 
narradas por alguns mais velhos como forma de garantir a segurança daqueles que viviam em meio aos conflitos com os colonizadores.

Por fim, o filme torna-se também um instrumento de diálogo entre diferentes gerações. No Encontro Nacional da Comissão Guarani Yvy Rupa, realizado na Tekoa Ko'enju, em 2013, um dos dias de reuniões transcorreu no Sítio Arqueológico de São Miguel Arcanjo. Na parte da manhã, anciãos e lideranças falavam sobre os significados daquele lugar na história dos Guarani e do quanto aquelas ruínas mostravam que as terras do entorno foram deixadas para que seus parentes ali vivessem. Na parte da tarde, os diálogos foram mediados pelo filme e novamente se teve a oportunidade de ouvir as lideranças, de gerações acima daquelas a que pertencem os membros do Coletivo Mbya-Guarani de Cinema. Suas falas afirmavam o vínculo dos Guarani com o lugar e despertaram outras reflexões daqueles jovens que produziram o filme. A possibilidade dessa troca estendeu-se ainda para outros espaços da aldeia, em dias posteriores ao encontro. As conversas e aconselhamentos que o filme despertara ficaram para além dos diálogos sobre a demarcação com instâncias político-administrativas e agentes indigenistas, mas proporcionaram refletir sobre processos de circulação e transformação de saberes impactados pela história do contato, pelo cotidiano na região e pelo processo de territorialização trazido por tais fenômenos.

\section{Considerações finais}

O mascaramento das contradições nas percepções da figura mítica de Sepé Tiaraju nas representações não indígenas, no Rio Grande do Sul, objetiva construir um herói com características aceitáveis ao imaginário de bravura e liberdade preponderante e, por isso, passível de ser cultuado. As atualizações do mito de Sepé Tiaraju instigam, sobretudo porque permitem analisar a pluralidade de motivações estabelecidas no âmago da comemoração, enquanto modalidade de relação entre o passado e o presente, através da criação do herói a ser festejado e das disputas que essa criação encerra no plano simbólico e suas decorrências.

Contudo, as percepções sobre os índios no Rio Grande do Sul não podem ser reduzidas a uma utilização unívoca do "interesse” da construção do 
regional via folclorização e fossilização da dinâmica cultural dos grupos. Os interesses são difusos e mesmo as identidades que os embasam são plurais, plenas de significado, e se encontram em disputa em um mundo que pode ser pensado, na perspectiva de Turner (1990) como uma selva de símbolos.

O que desejamos afirmar é que não estamos sendo educados para perceber esse outro. O índio genérico é diverso. Se de um lado a invisibilidade indígena no Rio Grande do Sul se plasma no discurso da homogeneidade de um índio imaginado e idealizado, de outro os Guarani afirmam que Sepé Tiaraju também é uma figura representativa da luta pela terra, mas de um modo completamente diverso daquele anunciado pelo turismo missioneiro, pelas religiões cristãs e pelo tradicionalismo gaúcho.

A experiência educacional de contato com os Mbya-Guarani na região das Missões remete à concepção de educação de Brandão (2002, p. 26), em que "educar é criar cenários, cenas e situações em que entre elas e eles, pessoas, comunidades, aprendentes de pessoas, símbolos sociais e significados de vida e do destino possam ser criados, recriados, negociados e transformados" e em que a percepção da diversidade cultural esbarra na aceitação da diferença, como menciona Bhabha (1998).

Nos filmes do Coletivo Mbya-Guarani de Cinema, Sepé é narrado por anciãos e lideranças como alguém que enganou os jesuítas e ajudou os Guarani a permanecerem em suas terras sem serem escravizados. Trata-se de uma percepção compartilhada por muitos Guarani, mas não necessariamente de um consenso.

Em Desterro guarani (2011), por exemplo, percebemos que o txeramoin Adolfo diz que Sepé era rico e que foi morto pelos jurua. Suas falas dirigem-se menos a Sepé e mais a um casal de xamãs que viveu naquela época - um karaí e uma kunhã karaí - que teriam sido os grandes responsáveis por aconselhar os Mbya e protegê-los. De modo análogo, é possível identificar significados distintos acerca da tava. Há quem a classifique como Tava Mirim, como lugar sagrado, e há quem a classifique apenas como tava, um lugar construído com os jurua kuery, apenas uma construção de pedra. O que permanece em todas as falas é o reconhecimento de São Miguel como um lugar importante para os Guarani, um dos caminhos que lhes foram abertos por seus antepassados.

Percebemos aqui um investimento em uma educação do olhar, no seu alargamento ao menos. Um processo que para Brandão (2002) está inserido

Horizontes Antropológicos, Porto Alegre, ano 21, n. 44, p. 201-227, jul./dez. 2015 
no âmbito da cultura, não se restringindo à escolarização constituindo-se em processos de tessitura de imaginários e práticas que nos permitem viver e que nos preparam para entender o mundo em que vivemos. Com relação à invisibilidade indígena é preciso conseguir ultrapassar a percepção estática de um índio comemorado como se branco fosse pelas virtudes que alguns grupos apostam engendrar. É necessário perceber a pluralidade simbólica de Sepé Tiaraju como signo de reversão que interessa também aos próprios Guarani, que situam na propriedade privada e nos limites geopolíticos elementos que produziram sua própria invisibilidade (Desterro guarani, 2011).

Nesse sentido, a popularização de determinadas percepções acerca de Sepé Tiaraju, na sua vivência como mito, para além da inculcação de uma representação partilhada, corresponde a um processo de produção e aquisição de conhecimento sobre a questão indígena. Para Ingold (2010, p. 19):

Não se trata de conhecimento que me foi comunicado; trata-se de conhecimento que eu mesmo construí seguindo os mesmos caminhos dos meus predecessores e orientado por eles. Em suma, o aumento do conhecimento na história de vida de uma pessoa não é um resultado de transmissão de informação, mas sim de redescoberta orientada.

Nesse sentido, a experiência do enskilment pode determinar o comportamento e tomadas de posição frente às populações indígenas com que nos deparamos cotidianamente nas cidades gaúchas, na medida em que colocam em diálogo percepções acerca dos índios reais, como no caso das relações estabelecidas com a reversão da invisibilidade dos Mbya-Guarani em São Miguel e em tantos outros espaços urbanos, no Rio Grande do Sul.

\section{Referências}

BARTHES, R. Mitologias. Rio de Janeiro: Bertrand Brasil, 2001.

BHABHA, R. O local da cultura. Belo Horizonte: UFMG, 1998.

BRANDÃO, C. R. Educação como cultura. São Paulo: Mercado das Letras, 2002. 
BRASIL. Câmara dos Deputados. Projeto de Lei n. ${ }^{\circ}$ 5.516-B, de 2005. (Do Sr. Marco Maia). Inscreve o nome de Sepé Tiaraju no Livro dos Heróis da Pátria; tendo pareceres: da Comissão de Educação e Cultura, pela aprovação (relator: Dep. Chico Alencar); e da Comissão de Constituição e Justiça e de Cidadania, pela constitucionalidade, juridicidade e técnica legislativa (relator: Dep. Gonzaga Patriota). Brasília, 2009. Disponível em: <http://www.camara. gov.br/proposicoesWeb/prop_mostrarintegra;jsessionid=1B63798AAA72 C9D62F3A2A7DE02F4074. node2 ?codteor=394274\& filename=Avulso+PL+5516/2005>. Acesso em: 19 dez. 2014.

BRUM, C. K. Sepé Tiaraju: o índio que os gaúchos querem viver. In: SILVA, G. F. da; PENNA, R.; CARNEIRO, L. C. da C. (Org.). RS Índio: cartografias sobre a produção do conhecimento. Porto Alegre: EDIPUCRS, 2009. p. 1528.

CARVALHO, J. M. de. Nação imaginária: memória, mitos e heróis. In: NOVAES, A. A crise do estado-nação. Rio de Janeiro: Civilização Brasileira, 2003. p. 349-418.

DESTERRO GUARANI. Direção: Daniel Ortega. Olinda: Vídeo nas Aldeias, 2011. Coleção Cineastas Indígenas Mbya-Guarani. 1 DVD.

GALLOIS, D.; CARELLI, V. Vídeo e diálogo cultural - experiência do Projeto Vídeo nas Aldeias. Horizontes Antropológicos, Porto Alegre, ano 1, n. 2, p. 49-57, 1995.

GAMA, B. da. O Uraguai. Porto Alegre: Mercado Aberto, 2002.

GÖERGEN, S. Marcha ao coração do latifúndio. Petrópolis: Vozes, 2004.

GRÜNEWALD, R. de A. Turismo e etnicidade. Horizontes Antropológicos, Porto Alegre, ano 9, n. 20, p. 141-159, out. 2003.

INGOLD, T. Pare, olhe, escute: visão, audição e movimento humano. Ponto Urbe, São Paulo, n. 3, 2008.

INGOLD, T. Da transmissão de representações à educação da atenção. Educação, Porto Alegre, v. 33, n. 1, p. 6-25, jan./abr. 2010. 
JESUS, S. C. de. Pessoas na medida: processos de circulação de saberes sobre o nhande reko Guarani na Região das Missões. 2015. Tese (Doutorado em Antropologia Social)-Centro de Filosofia e Ciências Humanas, Universidade Federal de Santa Catarina, Florianópolis, 2015.

LÉVI-STRAUSS, C. A estrutura dos mitos. In: LÉVI-STRAUSS, C. Antropologia estrutural. Rio de Janeiro: Tempo Universitário, 1996. p. 237266.

LÉVI-STRAUSS, C. História e dialética. In: LÉVI-STRAUSS, C. $O$ pensamento selvagem. Campinas: Papirus, 1997. p. 282-286.

LOPES NETO, J. S. Lendas do Sul. Porto Alegre: Martins Livreiro, 2000.

LUGON, C. A república "comunista” cristã dos guaranis. Rio de Janeiro: Paz e Terra, 1977.

MELIÁ, B. El guarani conquistado y reducido. Asunción: Universidad Católica Nuestra Señora de la Asunción, 1986. (Biblioteca Paraguaya de Antropología, v. 5).

MOKOI TEKOÁ PETEI JEGUATÁ - DUAS ALDEIAS, UMA CAMINHADA. Direção: Ariel Ortega, Jorge Morinico, Germano Benites. Olinda: Vídeo nas Aldeias, 2011. Coleção Cineastas Indígenas Mbya-Guarani. 1 DVD.

NÓS E A CIDADE. Direção: Ariel Ortega, Jorge Morinico, Germano Benites. Olinda: Vídeo nas Aldeias, 2009. Disponível em: <http://www. videonasaldeias.org.br/2009/video.php?c=81>. Acesso em: 19 dez. 2014.

OLIVEN, R. A parte e o todo: a diversidade cultural no Brasil-nação. 2. ed. Petrópolis: Vozes, 2006.

ORTIZ, R. Românticos e folcloristas. São Paulo: Olho d’Água, 1985.

PACHECO DE OLIVEIRA, J. Uma etnologia dos “índios misturados”? Situação colonial, territorialização e fluxos culturais. Mana, Rio de Janeiro, v. 4, n. 1, p. 47-77, 1998. 
PEREIRA, L. M. Assentamentos e formas organizacionais dos Kaiowá atuais: o caso dos “índios de Corredor”. Tellus, Campo Grande, ano 6, n. 10, p. 69-81, abr. 2006.

QUEVEDO, J. R. Guerreiros e jesuitas na utopia do Prata. São Paulo: EDUSC, 2000.

RAMOS, A. R. O índio hiper-real. Revista Brasileira de Ciências Sociais, São Paulo, v. 10, n. 28, p. 5-14, 1995.

RIO GRANDE DO SUL. Decreto $n^{\circ}$ 40.483, de 29 de novembro de 2000. Declara de utilidade pública, para fins de desapropriação, imóvel rural situado no Município de São Miguel das Missões - RS. Porto Alegre, 2000. Disponível em: <http://www.al.rs.gov.br/legis/M010/M0100099.ASP?Hid_ Tipo=TEXTO\&Hid_TodasNormas=2449\&hTexto=\&Hid_IDNorma=2449 $>$. Acesso em: 19 dez. 2014.

RIO GRANDE DO SUL. Lei $n^{\circ} 12.366$, de 03 de novembro de 2005. Declara Sepé Tiaraju como Herói Guarani Missioneiro Rio-grandense e dá outras providências. Porto Alegre, 2005. Disponível em: <http://www.al.rs.gov.br/ filerepository/repLegis/arquivos/12.366.pdf>. Acesso em: 19 dez. 2014.

SCHWARCZ, L. M. O espetáculo das raças. São Paulo: Companhia das Letras, 1993.

SCHWARCZ, L. M. Estado sem nação: a criação de uma memória oficial no Brasil do Segundo Reinado. In: NOVAES, A. A crise do estado-nação. Rio de Janeiro: Civilização Brasileira, 2003. p. 349-418.

SOUZA, J. O. C. de. Aos “fantasmas nas brenhas": etnografia, invisibilidade e etnicidades das alteridades originárias no sul do Brasil (Rio Grande do Sul). 1998. Tese (Doutorado em Antropologia Social)-Instituto de Filosofia e Ciências Humanas, Universidade Federal do Rio Grande do Sul, Porto Alegre, 1998.

SOUZA, J. O. C. de. Um salto do passado para o futuro: as comunidades indígenas e os direitos originários no Rio Grande do Sul. In: SILVA, G. F. da; PENNA, R.; CARNEIRO, L. C. da C. (Org.). RS Índio: cartografias sobre a produção do conhecimento. Porto Alegre: EDIPUCRS, 2009. p. 270-284. 
SOUZA, J. O. C. de; MORINICO, J. C. P. Ta’angá Tava Mirĩ: São Miguel (RS/Brasil) enquanto espectro da morada dos deuses aos Mbyá-Guarani. In LANGER, P. P.; CHAMORRO, G. (Org.). Missões, militância indigenista e protagonismo indígena: XIII Jornadas Internacionais sobre Missões Jesuíticas. São Bernardo do Campo: Nhanduti, 2012. p. 339-357.

TAVA: A CASA DE PEDRA. Direção: Patrícia Ferreira, Ariel Ortega, Ernesto de Carvalho, Vincent Carelli. Olinda: Vídeo nas Aldeias, 2011. 1 DVD.

TURNER, V. La selva de los símbolos. Madrid: Siglo Veintiuno, 1990.

Recebido em: 19/12/2014

Aprovado em: 05/06/2015 